\title{
Farklı Gamların Tavuk Köftelerdeki Bazı Özellikler Üzerine Etkileri
}

\author{
The Effects of Different Gums on Some Properties of Chicken Meatballs
}

\author{
Osman KILINÇÇEKER ${ }^{1, a}$, Özgür GÖLGE*2,b \\ ${ }^{1}$ Adlyaman Üniversitesi, Teknik Bilimler Meslek Yüksek Okulu, Gıda Isşleme Bölümü, 02040, Adlyaman \\ ${ }^{2}$ Alaaddin Keykubat Üniversitesi, ALTSO Turizm Meslek Yüksek Okulu, 07400, Alanya, Antalya
}

• Geliş tarihi / Received: 15.10 .2017 •Düzeltilerek geliş tarihi / Received in revised form: 19.02.2018 • Kabul tarihi / Accepted: 26.03 .2018

\begin{abstract}
$\ddot{O} \mathbf{z}$
Bu çalışmada; karboksimetil selüloz, agar agar, tara ve keçiboynuzu gamlarının \% 1 oranında tavuk köftelere ilavesinin ürünün bazı nitelikleri üzerine etkileri araştırılmıştır. Hazırlanan pişmemiş köftelerde renk nitelikleri belirlenirken, 175 ${ }^{\circ} \mathrm{C}$ 'de $5 \mathrm{dk}$ kızartılan örneklerde; kızartma sonrası pişme verimi, çap azalması, renk değerleri, nem tutma oranı, yağ emme oranı ve duyusal nitelikler saptanmıştır. Gam ilavesi ile pişmemiş örneklerde $L$ (parlaklık) değeri değişim göstermezken, $a$ (kırmızılık) ve $b$ (sarılık) değerlerinin düştüğü anlaşılmıştır. Kızarmış köftelerde; en yüksek pişme verimi değerleri agar agar ve keçiboynuzu gamı ile hazırlanan örneklerde bulunmuş, çap azalma değerleri ise farklılık göstermemiş̧ir. Kızarmış örneklerin renk değerlerinde; $L$ ve $b$ değeri keçiboynuzu gamı ile hazırlanan örneklerde en yüksek bulunmuş, $a$ değerinin ise gam ilavesinden etkilenmediği anlaşılmıştır. Kızartılan ürünlerde agar agar gamı ve keçiboynuzu gamı ilavesi tutulan nem oranını artıırken, özellikle keçiboynuzu gamı emilen yağ oranını azaltmıştır. Benzer şekilde, köftelerin duyusal analizlerinde; agar agar gamı ve keçi boynuzu gamı ilavesi görünüş, renk, koku ve tat puanlarını yükseltmiştir. Bütün sonuçlara bağlı olarak gam ilavesinin tavuk etinden hazırlanan pişmemiş köfte renginde etkili olmayacağı, ancak kızarmış köftelerde kaliteyi artırabileceği belirlenmiş olup, en iyi uygulama olarak agar agar gamı veya keçiboynuzu gamının tavsiye edilebileceği anlaşılmıştır.
\end{abstract}

Anahtar kelimeler: Gam, Kalite Özellikleri, Kızartma, Tavuk Köfte

\begin{abstract}
In this study; addition of $1 \%$ carboxymethyl cellulose, agar agar, tara and locust bean gums to chicken meatballs during production with aspect of effect on quality was investigated. Colour parameters were measured in raw samples; yields, diameter reductions, colour parameters, moisture retentions, fat absorptions and sensory properties of fried samples at 175 oC for 5 min were determined. Results indicate that; L values of raw samples did not show any significant change; $a$ and $b$ values of these samples decreased. Samples with agar agar and locust bean gums had higher yields than other gums, whereas diameter reductions of fried samples were similar. L and $b$ values of fried samples with locust bean gum were higher than others. It was observed that a values were not affected by gum addition. Despite agar agar and locust bean gums addition increased the moisture retentions of fried samples; locust bean gum decreased the fat absorptions. Similarly, agar agar and locust bean gums increased the appearance, colour, and taste scores from sensory properties. Depending on all the results; It has been determined that addition of gum can not be effective on the color of raw meatballs prepared from chicken meat but may increase the quality of fried samples and it has been understood that the agar agar or locuts bean gum can be recommended as a best practice.
\end{abstract}

Keywords: Gum, Quality Properties, Frying, Chicken Meatball

\footnotetext{
*b Özgür GÖLGE; ozgur.golge@alanya.edu.tr; Tel: (0242) 5106183 - 6200; orcid.org/0000-0001-5020-339X

a orcid.org/0000-0002-5222-1775
} 


\section{Giriş}

Dünyada eğitim ve kültürel gelişmelere bağl1 olarak kaliteli iş gücü artarken, bu güç içerisinde çalışan kadın sayısı da artmıştır. Buna bağlı olarak iş hayatı içerisinde yer alan kadınlar zamandan tasarruf etmek için hazır gıdalara yönelmişlerdir. Ayrica fast food zincirlerinin artması da bu talebe destek olmuştur (Kılınççeker ve Alkış, 2015).

Son zamanlarda hazır yemekler sofralarda daha fazla yer alırken, beraberinde obezite, kanser, tansiyon ve diyabet hastalığı gibi problemleri de artırmıştır (Demirci vd., 2014; K1lıççeker, 2017). Dolayısıyla hazır yemek üreticileri farklı ürünler üzerinde yoğunlaşırken; antioksidan, antimikrobiyal özellikteki veya nem ve yă̆ transferine karşı etkili olan bazı bileşenleri kullanarak insanlara daha sağlıklı ve kaliteli gıda üretmeye yönelmişlerdir. Çeşitli uygulamalarla son üründe sağlık açısından istenen kaliteyi elde ederken, ürünlerde görülebilecek fiziksel, kimyasal ve duyusal özellikleri de korumaya, hatta artırmaya çalışmaktadırlar. Yaptıkları ARGE çalışmaları ile farklı katkı maddelerini veya işleme proseslerini kullanarak tüketicilere alternatifler sunmaya çabalamaktadırlar (Modi vd., 2009; Cava vd., 2012).

Bahsedilen uygulamalara en iyi örnek et ve ürünleri sektörüdür. Özellikle tavuk eti ürünleri ucuz ve kolay bulunabilir olması nedeni ile dünya nüfusunun büyük bir çoğunluğunun günlük beslenmesinde önemli bir yere sahiptir. Buna karşın işlemesi zor bir gida grubudur. Bu nedenle konu ile ilgili bilim adamları ve beyaz etlerden üretim yapan işletmeler farklı uygulamalara yönelerek, hem ürün kalitesini hem de pazar payını artırmaya çalışmaktadırlar. $\mathrm{Bu}$ amaçla yapılan çalışmalara Rahimi vd. (2018) tarafindan kızılötesi teknolojisi kullanılarak gerçekleştirilen tavuk köfte denemesi ile Jing vd. (2018) tarafindan sodyum alginat kullanılarak tavuk göğüs etinde su tutma kapasitesi üzerine yapılan araştırmalar örnek verilebilir. Elde edilen sonuçlarda; yapılan uygulamalar ile ilk çalışmada son ürün olarak elde edilen kızartılmış köftelerde yă oranı azalırken, ikinci çalışmada, pişmiş ürünün su tutma kapasitesinin arttığı vurgulanmıș ve sektöre alternatif işlemler olarak tavsiye edilmişlerdir.

Gamlar da bu sektörde kullanılabilen katk1 maddeleri içerisinde önemli olan başka bir örnektir. Suyu bağlayıcı özelliği olan bu maddeler çok düşük oranda kullanılarak üretim esnasında görülebilen şekil bozukluğu ve dağılma gibi kusurları engellerken, ürün depolamada görülebilen oksidasyon, fire kaybı ve renk değişimi gibi problemleri de azaltabilmektedirler. Ayrıca çoğunlukla ürün rengini olumsuz etkileyecek renk özeliklerinin olmaması, tatsız ve kokusuz olmaları başka bazı avantajlarıdır (Demirci vd., 2014; Gibis vd., 2015; K1lınççeker, 2017).

Buna karşın yapılan araştırmalara bakıldığında, beyaz et sektöründe farklı gamların kullanımı ile ilgili çalışmaların az olduğu anlaşılmıştır. Oysa geçmişteki uygulamaların 1şı̆̆ında farklı fonksiyonel özelliklerinden dolayı kullanılan gam türünün tespitinin önemli olabileceği düşünülmektedir. Anlatılanlara bağlı olarak bu çalışmada karboksimetil selüloz, agaragar, tara ve keçiboynuzu gamlarının \% 1 oranında tavuk köfte üretiminde kullanımının ürünün bazı özellikleri üzerindeki etkisi araştırılmıştır. Çalışmada en iyi sonuçlar belirlenirken tüketiciye farklı alternatifler sunulmaya çalışılmıştır.

\section{Materyal ve Metot}

$\mathrm{Bu}$ çalışmada kullanılan karboksimetil selüloz, agar agar, tara ve keçiboynuzu gamları Kimbiotek Kim. Mad. San. (İstanbul) firmasından satın alınmıştır. Tavuk göğüs eti ve diğer malzemeler Adıyaman'daki bazı işletmelerden temin edilmiştir. Köftelerin kızartılması için mini kızartma makinası (Tefal) ve ayçiçek yağı (Yudum) kullanılmıştır. Başlangıçta donmuş tavuk gögüs etleri $+4{ }^{\circ} \mathrm{C}^{\prime}$ de $16-18$ saat bekletilip çözülmüş ve kıyma makinasının 3 mm'lik aynasında kıyılmıştır. Daha sonra \% 93.5 et $+\% 5$ galeta unu $+\% 1.5$ tuz içerecek şekilde ön karışım hazırlanıp $10 \mathrm{dk}$ yoğurulmuştur. Sonra her bir örnek için; bu karışımdan $99 \mathrm{~g}$ alınıp $1 \mathrm{~g}$ gam eklenerek çalışma örnekleri hazırlanmıştır. Tekrar iyice yoğrulup $20 \mathrm{dk}$ dinlendirildikten sonra $19 \mathrm{~g}$ ağırlığında ve eşit çapta yuvarlak köfteler hazırlanmıştır. Kontrol örneği olarak gam içermeyen grup kullanılmıştır. Her bir örnek için 4 köfte $175{ }^{\circ} \mathrm{C}$ de derin yağda $5 \mathrm{dk}$ kızartılmış ve ilgili analizler yapılmıştır. Kızartmada kullanılan yağ her bir örnek için yenilenirken, duyusal analizler için aynı pişirme yöntemi ve parametreler kullanılarak hazırlanan köfte örneklerine puanlama testi uygulanmıştır. Çalışma esnasında kızartılmamış ve kızartılmış köftelerdeki renk değerleri olan $L$ (açıklıkkoyuluk), $a$ (kırmızılık-yeşillik) ve $b$ (sarılıkmavilik) bir kolorimetre (Konica Minalto, Inc., Osaka, Japan) kullanılarak ölçülmüştür. Kızartma sonrası pişme verimi ve çap azalması değerleri hassas terazi ve elektronik kumpas kullanımı ile 
Kurt ve Kılınççeker'in (2012) çalışmalarında belirtildiği gibi, aşağıdaki formüller yardımı ile saptanmıştır. Pişme verimi ve çap azalması ölçümleri kızartmadan $2 \mathrm{dk}$ sonra yapılmış, pişme verimi hesaplamalarında 4 köfte kullanılmıştır. Çap azalması ölçümlerinde ise 4 köftenin her biri için üçer farklı noktadan ölçümler yapılmış ve ortalamalar alınmıştır.

Pişme verimi $(\%)=\frac{\text { Kızarmış köfte ağırlı̆̆ı }}{\text { Pişmemiş köfte ağırlığı }}$ X 100

Çap azalması $(\%)=$

$\frac{\text { Pişmemiş köfte çapı-Kızarmış köfte çapı }}{\text { Pişmemiş köfte çapı }}$ X 100

Nem tayini; örneklerden k1zartma öncesi ve kızartma sonrası alınarak $105{ }^{\circ} \mathrm{C}$ 'de etüvde kurutma ile, yağ tayini ise; hekzan kullanarak soxhelet ekstraksiyon metodu ile yapılmıştır (AOAC, 2002). Bu değerlere bağl1 olarak nem tutma ve yağ emilim değerleri ise aşağıdaki formüllere göre hesaplanmıştır.

Nem tutma $(\%)=$

$\frac{\text { Kızarmış köftedeki nem (\%) }}{\text { Pișmemiș köftedeki nem (\%) }} x$ pişme verimi

Yağ emilim (\%) = kızarmış köftedeki yağ (\%) -

pişmemiş köftedeki yağ (\%)

Köftelerin duyusal olarak değerlendirilebilmeleri için, önceki kısımda belirtildiği şekilde, köfte hamurlarından sırası ile 6'şar örnek hazırlanarak benzer sıcaklık ve sürede kızartılmıştır. Kızartmayı takiben $2 \mathrm{dk}$ sonra, 10 kişilik gıda işleme bölümü öğrencisine, Gökalp vd. (1999)'nde anlatıldığı gibi hedonik derecelendirme skalasına göre puanlama testi uygulanmıştır. Panelistlerden beğeni derecelerine bağlı olarak köftelere 1-9 arasında puan vermeleri istenmiştir. Çalışma iki tekerrür ve üç paralel olarak yürütülmüsşür. Elde edilen verilere varyans analizi uygulanmış, önemli bulunan ortalamalar $\mathrm{P}<0.01$ ve $\mathrm{P}<0.05$ düzeyinde Duncan çoklu karşılaş̧ırma testine tabii tutulmuşlardır. Sonuçlar ortalama \pm standart sapma olarak verilmiştir (SPSS, CHICAGO, IL, USA).

\section{Bulgular ve Tartışma}

Piyasada ticareti yapılan et ve ürünlerinin rafta iken satışında en etkili özelliklerinden bir tanesi renktir. Beyaz etlerden elde edilen köfte gibi bazı pişmemiş ürünlerde parlak kırmızımsı-sarı rengin yoğunluğu talebi olumlu etkileyebilmektedir. $\mathrm{Bu}$ nedenle üreticiler katk1 maddesi olarak üründe bahsedilen tarzda renk yoğunluğunu artıracak malzemeleri seçmektedirler. $\mathrm{Bu}$ çalışmada kızartılmamış köftelerdeki renk değerleri Tablo 1 'de verilmiştir. Tabloya bakıldığ 1 zaman $L$ değerlerinin bütün örneklerde istatistiki olarak farksız $(\mathrm{P}>0.05)$ olduğu ve 46.62-51.06 aralığında değiştiği anlaşılabilir. Ancak, kırmızı renk yoğunluğunu gösteren $a$ değeri en yüksek 4.41 ve 4.11 olarak kontrol ve keçiboynuzu gamı içeren örneklerde ölçülürken, sarı renk yoğunluğunu gösteren $b$ değeri en yüksek 12.60 ve 11.78 olarak kontrol ve karboksimetil selüloz ile hazırlanan köftelerde saptanmıştır $(\mathrm{P}<0.05)$. Sonuçlardan da anlaşılacağı üzere gam kullanımı, pişmemiş köftelerin özellikle kırmızılık ve sarılık değerlerini etkilemiştir. Kırmızılık değerlerinde keçiboynuzu gamının, sarılık değerlerinde karboksimetil selülozun yüksek sonuç vermesi diğer gamlara kıyasla daha yoğun renk pigmenti içermelerine bağlanabilir. Bu çalışmaya benzer şekilde; Cava vd. (2012)'nin farklı lifler ile, Demirci vd. (2014)'nin farklı gamlar ile hazırladıkları beyaz et ürünlerinde pişmemiş örneklerin renk değerlerinin farklılık gösterdiği ve bu farklılı̆̆ın liflerin ve gamların doğal renk özellikleri ile ilgili olduğu vurgulanmıştır.

Is1 işlem uygulanan et ürünlerinde yapısal ve fiziksel olarak birçok değişim meydana gelmektedir. Özellikle su kaybı ve proteinlerdeki denatürasyon bu değişimler üzerinde etkili olmaktadırlar. Kızartma gibi 1sıl işlem sonrası meydana gelen bu değişimlerle ağırlık kaybı, şekil bozukluğu ve renk gibi bazı nitelikler değişirken, bunlara bağlı olarak ambalajlama işleminin olumsuz etkilenmesi de söz konusu olabilmektedir (Demirci vd., 2014; K1lınççeker, 2017). Tablo 2'ye bakıldığında bu özellikler üzerinde gamların etkisini gösteren sonuçlar görülebilir. Elde edilen değerlere göre; gamlar ile hazırlanan köftelerde kızartma sonrası pişme verimi en yüksek $\% 86.74$ olarak agar agar ile hazırlanan örneklerde saptanmıştır $\quad(\mathrm{P}<0.01)$. Çap azalmasında istatistiksel olarak bir farklılık gözlenmemiş $(\mathrm{P}>0.05)$ ve bu değerin \% $\quad-1.34$ ile $\% 0.23$ arasında olduğu anlaşılmıştır. Yapılan diğer çalışmalara bakıldığında; Modi vd. (2009) tarafindan et köftelere karagenan gamı eklemenin pişme verimini artırdığ çalışmada gamın proteinlerin su ile kompleks oluşturmasını kolaylaştırdı ğı belirtilerek, fire kaybını azalttığı vurgulanmıştır. Gibiş vd. (2015) et köftelere \% $\quad 0.5-3$ oranında mikrokristalli selüloz eklediklerinde kızartma sırasındaki nem kaybının azaldığını gözlemişlerdir. 
Tablo 1. Farklı gamların pişmemiş köftelerdeki renk değerleri üzerine etkileri.

\begin{tabular}{llll}
\hline \multicolumn{1}{c}{ Gam türü } & \multicolumn{1}{c}{$a$} & \multicolumn{1}{c}{$b$} \\
\hline Kontrol & $51.06 \pm 2.17$ & $4.41 \pm 0.24^{\mathrm{a}}$ & $12.60 \pm 0.38^{\mathrm{a}}$ \\
Karboksimetil selüloz & $48.54 \pm 0.39$ & $3.93 \pm 0.16^{\mathrm{bc}}$ & $11.78 \pm 0.14^{\mathrm{ab}}$ \\
Agaragar & $48.48 \pm 2.14$ & $3.94 \pm 0.18^{\mathrm{bc}}$ & $11.11 \pm 0.51^{\mathrm{bc}}$ \\
Tara & $48.80 \pm 1.90$ & $3.61 \pm 0.01^{\mathrm{c}}$ & $11.52 \pm 0.66^{\mathrm{abc}}$ \\
Keçiboynuzu & $46.62 \pm 1.36$ & $4.11 \pm 0.11^{\mathrm{ab}}$ & $10.43 \pm 0.25^{\mathrm{c}}$ \\
\hline
\end{tabular}

a-c: her bir sütundaki istatistiki farkl1lığ 1 göstermektedir $(\mathrm{P}<0.01$ veya $\mathrm{P}<0.05)$.

Tablo 2. Farklı gamların kızarmış köftelerdeki pişme verimi, çap azalması ve renk değerleri üzerine etkileri.

\begin{tabular}{llllcc}
\hline \multicolumn{1}{c}{ Gam türü } & Pişme verimi (\%) & Çap azalması (\%) & $L$ & $a$ & $b$ \\
\hline Kontrol & $83.90 \pm 0.47^{\mathrm{c}}$ & $-1.18 \pm 1.11$ & $43.55 \pm 0.45^{\mathrm{c}}$ & $13.79 \pm 1.07$ & $21.15 \pm 0.15^{\mathrm{b}}$ \\
Karboksimetilselüloz & $81.57 \pm 0.08^{\mathrm{d}}$ & $0.05 \pm 0.90$ & $45.08 \pm 1.08^{\mathrm{b}}$ & $13.59 \pm 0.01$ & $21.67 \pm 0.41^{\mathrm{ab}}$ \\
Agaragar & $86.74 \pm 0.12^{\mathrm{a}}$ & $0.23 \pm 1.72$ & $46.09 \pm 0.48^{\mathrm{ab}}$ & $13.70 \pm 0.10$ & $22.14 \pm 0.90^{\mathrm{ab}}$ \\
Tara & $83.10 \pm 0.21^{\mathrm{c}}$ & $-0.98 \pm 2.65$ & $45.22 \pm 0.10^{\mathrm{b}}$ & $13.84 \pm 0.47$ & $21.85 \pm 0.20^{\mathrm{ab}}$ \\
Keçiboynuzu & $85.20 \pm 0.56^{\mathrm{b}}$ & $-1.34 \pm 0.32$ & $47.47 \pm 0.25^{\mathrm{a}}$ & $14.20 \pm 0.16$ & $22.63 \pm 0.10^{\mathrm{a}}$ \\
\hline
\end{tabular}

a-d: her bir sütundaki istatistiki farklılığ göstermektedir $(\mathrm{P}<0.01$ veya $\mathrm{P}<0.05)$.

Başka bir çalışmada; et köftelere \% 0-5 aralığında aloe vera eklemenin pişirme kaybını önemli oranda azalttığı, aloe veranın bir hidrokolloid gibi davranarak pişme esnasında su tutma kapasitesini artırdı̆̆ belirtilmiştir (Soltanizadeh ve GhiasiEsfahani, 2015). Bizim sonuçlarımız da bahsedilenlerle benzeşmektedir.

Gamlar ile hazırlanan köftelerin kızartma sonrası renk değerleri özellikle tüketim esnasında önemli bir husustur. Şeklin yanı sıra, kızartma sonrası oluşan kırmızı-sarı renk yoğunluğu görselliği artırarak tercihi olumlu etkilemektedir. $\mathrm{Bu}$ nedenle çalışmamızda kızartma sonrası renk değerleri de belirlenmiş ve sonuçlar Tablo 2'de sunulmuştur. Bahsedilen değerlere bakıldığ 1 zaman; parlaklığ gösteren $L$ değeri en yüksek 47.47 olarak keçiboynuzu gamı ile hazırlanan örneklerde ortaya çıkmıştır $(\mathrm{P}<0.01)$. Kırmızılık değerleri örnekler arasında değişim göstermezken $(\mathrm{P}>0.05)$, sarılık yoğunluğunu gösteren $b$ değerlerinde en yüksek sonuç 22.63 olarak yine keçiboynuzu gamı ile hazırlanan köftelerde ölçülmüsşür $(\mathrm{P}<0.05)$. Benzer şekilde, Demirci vd. (2014) ve K1lınççeker ve Y1lmaz'ın (2016) et köftelerde gam kullanımı ile yaptıkları çalışmalarda renk değerlerinin pişme sonrası etkilendiği belirtilmiştir. $\mathrm{Bu}$ çalışmalarda kullanılan gamların karoten gibi doğal renk maddelerinin pişme sonrası renk oluşumunu etkilediği vurgulanmıştır. Aynı şekilde bizim çalışmamızda da bahsedilen renk maddelerinin son ürün rengi üzerinde etkili olduğu düşünülmektedir.

Kızartılan gıdalar için önemli olan diğer iki önemli özellik nem tutma ve yă emme oranlarıdır. Derin yağda kızartma esnasında protein yapılarının bozulması ile suyu bağlama yetenekleri azalır, dolayısıyla ürün yapısında tutulabilen su oranı düşer. Buna karşın içeriye emilen yağ miktarı artar. $\mathrm{Bu}$ değişim sağlıklı beslenme için istenmeyen bir durumdur. Üründe yap1 sertleşebildiği gibi kalori değeri de önemli düzeyde artmaktadır. Bu nedenle üreticiler benzer tarz gıda üretiminde gam gibi çeşitli katkı maddelerini bileşimde kullanarak bu problemleri azaltma üzerinde çalışmalar yapmaktadırlar (Pinero vd., 2007; K1lınççeker, 2017). Yapılan çalışmada kızartılan örneklerin nem tutma ve yağ emme oranları Şekil 1'de gösterilmiştir. Bazı örneklerde istatistiksel olarak benzerlik saptanırken, şekle göre en yüksek nem tutma oranlarının \% 76.63 olarak agar agar ve \% 74.5 olarak keçiboynuzu gamı ile hazırlanan köftelerde ortaya çıktığı anlaşılmaktadır $(\mathrm{P}<0.05)$. Buna karşın en düşük yağ emme oranlarının $\% 0.63$ olarak karboksimetil selüloz ve \% 0.6 olarak keçiboynuzu gamı ile üretilen örneklerde olduğu belirlenmiştir $(\mathrm{P}<0.05)$. Benzer şekilde, Demirci vd. (2014)'nin çalışmasında dana etinden üretilmiş köftelere gam eklemenin pişme esnasındaki nem kaybını azalttığı ve özellikle guar gamının etkili olduğu vurgulanmıştır. Ayrıca, Kilıççeker ve Y1lmaz (2016) yaptıkları çalışmada farklı gam eklemenin et köftelerde kızartma esnasında nem tutma oranını artırdığını belirlerken, Kılınççeker (2017) tara, tragakant ve agaragar gamlarının tavuk köftelere ilavesi ile yaptığı çalışmada kızartma esnasında köftelerin nem kaybının ve yağ emilim oranlarının azaltılabileceğini ortaya koymuştur. Çalışmamıza benzer sonuçlar Ulu (2006), Kurt ve Kılınççeker (2012), Yaşarlar vd. (2014) ve Soltanizadeh ve Ghiasi-Esfahani (2015) tarafindan da belirlenmiştir. 


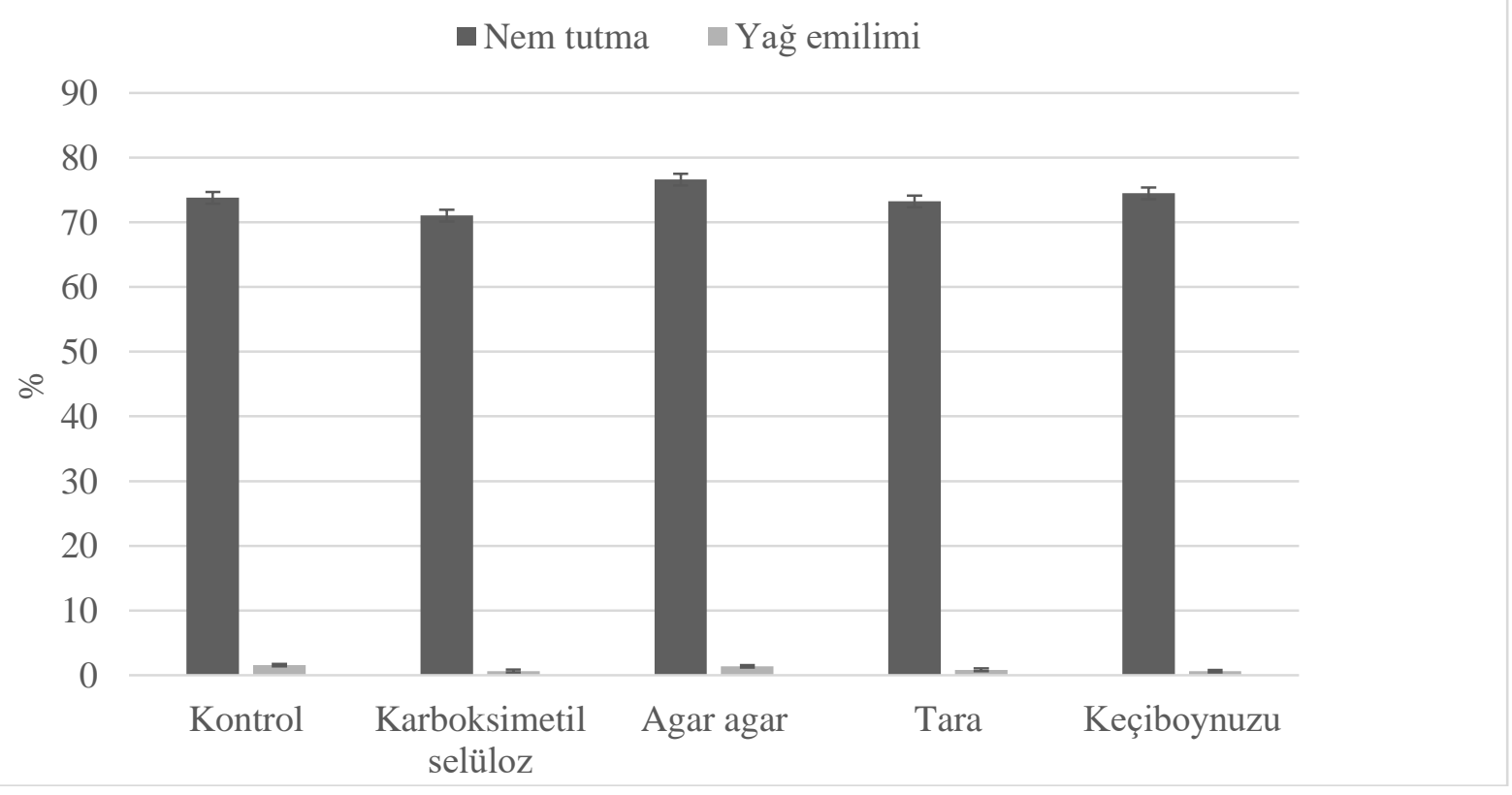

Şekil 1. Farklı gamların kızarmış köftelerdeki nem tutma ve yağ emilim değerleri üzerine etkisi

Yeni geliştirilen ürünlerde önemli olan başka bir özellik grubu da duyusal niteliklerdir. Özellikle satış ve tüketim esnasında tüketiciyi etkileyerek satış üzerinde etken olmaktadırlar. $\mathrm{Bu}$ nedenle belirlenmelerinin önemli olduğu düşünülmektedir. Bahsedilen kriterler ile ilgili sonuçlar Tablo 3'te verilmiştir. Sonuçlardan da anlaşılabileceği gibi, gamlar koku ve tekstür hariç diğer duyusal özellikler üzerinde etkili olmuşlardır $(\mathrm{P}<0.05)$. En iyi puanlara bakıldığı zaman; özellikle agar agar ve keçiboynuzu gamları ile hazırlanan örnekler görünüş (7 ve 7.05$)$, renk (6.90 ve 7.20$)$ ve tat (6.15 ve 6.30) özelliklerinde en yüksek skorlara sahip gruplar olmuşlardır. Bu sonuçlara göre; bu iki gamın kızartılmış örnek renk değerlerinin yüksek olmasından da anlaşılacağı üzere, oluşturdukları rengin beğenilmesi görünüş ve renk puanlarını artırırken, yine bu gamların nem tutma oranlarının yüksek olması ile oluşturdukları suluçıtır yapının tat puanlarını artırdığ düşünülmektedir. Benzer sonuçlar Kılınççeker (2017) tarafindan farklı gamlar ile hazırlanan tavuk köftelerde de belirlenmiștir. Bahsedilen araştırmada genel olarak gam katılıp kızartılan örneklerden renk değerleri ve nem tutma oranları yüksek çıkanların duyusal puanlarının da yüksek olduğu gözlenmiştir. Ayrıca, Demirci vd. (2014) tarafından köftelere farklı gam katılarak ve İbrahim vd. (2011) tarafindan tavuk köftelere maltodekstrin ve nişasta katılarak yapılan çalışmalarda da benzer sonuçlar bulunmuştur. Bahsedilen çalışmalarda et ürünlerine hidrokolloid özellik sergileyen malzemeleri ilave etmenin duyusal özellikleri iyileştirdiği tespit edilmiştir.

\section{Sonuç}

Çalışma sonucunda tavuk köfte yapımında farklı gamların ilavesinin avantajlı olabileceği anlaşılmıştır. Gam ilavesi pişmemiş örneklerin $L$ değerlerini değiştirmezken, genel olarak $a$ ve $b$ değerlerini düşürdüğü tespit edilmiş̧ir. Kızarmış örneklerde pişme verimi; agar agar gamı ve keçiboynuzu gamları ilavesi ile artış gösterirken, çap azalması oranları gam ilavesinden etkilenmemiştir.

Tablo 3. Farklı gamların kızarmış köftelerdeki duyusal değerler üzerine etkileri.

\begin{tabular}{llllll}
\hline Gam türü & Görünüs & Renk & Koku & Tat & Tekstür \\
\hline Kontrol & $5.65 \pm 0.92^{\mathrm{ab}}$ & $5.30 \pm 0.99^{\mathrm{bc}}$ & $4.90 \pm 0.56$ & $5.20 \pm 0.28^{\mathrm{bc}}$ & $5.30 \pm 0.14$ \\
Karboksimetil & $4.65 \pm 0.49^{\mathrm{b}}$ & $4.50 \pm 0.71^{\mathrm{c}}$ & $4.40 \pm 0.71$ & $4.50 \pm 0.14^{\mathrm{c}}$ & $4.40 \pm 0.00$ \\
selüloz & & & & \\
Agaragar & $7.00 \pm 0.28^{\mathrm{a}}$ & $6.90 \pm 0.00^{\mathrm{ab}}$ & $5.60 \pm 0.00$ & $6.15 \pm 0.49^{\mathrm{ab}}$ & $6.10 \pm 0.14$ \\
Tara & $4.70 \pm 0.42^{\mathrm{b}}$ & $4.40 \pm 0.71^{\mathrm{c}}$ & $4.95 \pm 0.35$ & $5.35 \pm 0.07^{\mathrm{abc}}$ & $5.05 \pm 0.07$ \\
Keçiboynuzu & $7.05 \pm 0.64^{\mathrm{a}}$ & $7.20 \pm 0.71^{\mathrm{a}}$ & $6.00 \pm 0.71$ & $6.30 \pm 0.56^{\mathrm{a}}$ & $5.70 \pm 1.41$ \\
\hline
\end{tabular}

a-c: her bir sütundaki istatistiki farkl1lığı göstermektedir $(\mathrm{P}<0.01$ veya $\mathrm{P}<0.05)$. 
Ayrıca kızarmış örneklerde keçiboynuzu gamı $L$ ve $b$ değerlerini artırmış, $a$ değerleri ise gam ilavesinden etkilenmemiştir. Kızartma esnasındaki nem tutma oranları agar agar gamı ve keçiboynuzu gamı ilavesi ile artarken, yağ emilim oranı keçiboynuzu gamı ilavesi ile düşmüştür. Duyusal analizlerde ise en avantajlı grup agar agar gamı ve keçiboynuzu gamı ile hazırlanan örnekler olmuştur. Bütün sonuçlara bağlı olarak; gam ilavesinin pişmemiş örneklerdeki renk değerlerinde avantajlı olmadığı anlaşılırken, kızarmış örneklerde bazı kalite niteliklerini iyileştirebileceği ve özellikle agar agar ve keçiboynuzu gamlarının tavsiye edilebileceği sonucuna varılmıştır.

\section{Kaynaklar}

AOAC., 2002. Offical Methods of Analysis (17 $7^{\text {th }}$ ed.). Association of Official Analytical Chemists, Washington DC.

Cava, R., Ladero, Cantero, L.ve Ramirez, V.R., 2012. Assessment of different dietary fibers (tomato fiber, beet root fiber, and inulin) for the manufacture of chopped cooked chicken products. Journal of Food Science, 77(4), 346-352.

Demirci, Z.O., Y1lmaz, I. ve Demirci, A.Ş., 2014. Effects of xanthan, guar, carrageenan, and locust bean gum addition on physical, chemical, and sensory properties of meatballs. Journal of Food Science and Technology, 51(5), 936-942.

Gibis, M., Schuh, V. ve Weiss, J., 2015. Effects of carboxy methyl cellulose (CMC) and micro crystalline cellulose (MCC) as fat replacers on the microstructure and sensory characteristics of fried beef patties. Food Hydrocolloids, 45(3), 236-246.

Gökalp, H.Y., Kaya, M., Tülek, Y. ve Zorba, Ö., 1999. Et ve Ürünlerinde Kalite Kontrolü ve Laboratuvar Uygulama Kılavuzu (Üçüncü Bask1), Atatürk Üniversitesi Yayınlar1, Yayın No: 318, Erzurum, 287s.

Ibrahim, M. A., Salama, M. F. ve Hussein, A. A., 2011. Production of low-fat chicken burger. Australian Journal of Basic and Applied Science, 5 (1), 3149-3154.

K1lınççeker, O. 2017. Tara, tragakant ve agar agar gamlarının tavuk köftelerde kullanımı. Gida, 42(3), 219-228.
Kılınççeker, O. ve Alkış A. K., 2015. Buğday proteini ve bezelye proteini ile hazırlanan çözelti tipi kaplamaların tavuk köftelerde kullanımı. Adıyaman Üniversitesi Mühendislik Bilimleri Dergisi, 3(2), 48-53.

K1lınççeker, O. ve Y1lmaz, M.T., 2016. Effects of different gums on the some properties of fried beef patties. Carpathian Journal of Food Science and Technology, 8(2), 63-70.

Kurt, Ş. ve Kilınçęeker, O., 2012. The effects of cereal and legume flours on the quality characteristics of beef patties. Kafkas Universitesi Veteriner Fakültesi Dergisi, 18(5), 725-730.

Modi V. K, Yashoda K. P. ve Naveen S. K., 2009. Effect of carrageenan and oatflour on quality characteristics of meat kofta. International Journal of Food Properties, 12(1), 228-242.

Pinero, M.P., Parra, K., Huerta-Leidenz, N., Moreno, L.A., Ferrer, M., S. Araujo ve Barboza., Y., 2008. Effect of oat's soluble ( $\beta$-glucan) as a fat replacer on physical, chemical, microbiological and sensory properties of low-fat beef patties. Meat Science, 80(3), 675-680.

Rahimi, D., Kashaninejad, M., Ziaiifar, A.M. ve Mahoonak, A.S., 2018. Effect of infrared final cooking on some physico-chemical and engineering properties of partially fried chicken nugget. Innovative Food Science\&Emerging Technologies, 47(6), 18.

Soltanizadeh, N. ve Ghiasi-Esfahani, H., 2015. Qualitative improvement of low meat beef burger using aloe vera. Meat Science, 99(1), 75-80.

Ulu, H., 2006. Effects of carrageenan and guar gum on the cooking and textural properties of low fat meatballs. Food Chemistry, 95(4), 600-605.

Yao, J., Zhou, Y., Chen, X., Ma, F., Li, P. ve Chen, C., 2018. Effect of sodium alginate with three molecular weight forms on the water holding capacity of chicken breast myosin gel. Food Chemistry, 239(1), 11341142. 